\title{
Application of the Consolidated Framework for Implementation Research Model to Design and Implement an Optimization Methodology within an Ambulatory Setting
}

\author{
Jonathan C. Touson ${ }^{1} \quad$ Namita Azad ${ }^{1} \quad$ Jennifer Beirne ${ }^{1} \quad$ Corinne R. Depue $^{1} \quad$ Timothy J. Crimmins $^{1}$ \\ Jonathan Overdevest ${ }^{2}$ Rosalie Long ${ }^{1}$ \\ ${ }^{1}$ Columbia Faculty Practice, Columbia University Irving Medical \\ Center, New York, New York, United States \\ 2 Department of Otolaryngology, Columbia University Irving Medical \\ Center, New York, New York, United States \\ Address for correspondence Namita Azad, BS, MPH, MS, Columbia \\ Faculty Practice, Columbia University Irving Medical Center, 21 \\ Audubon Avenue, New York, NY 10032-3784, United States \\ (e-mail: na2811@cumc.columbia.edu).
}

Appl Clin Inform 2022;13:123-131.

\section{Abstract}

Keywords

- electronic health records

- optimization

- ambulatory

- COVID-19

- consolidated framework for implementation research
Background Following the implementation of a new electronic health record (EHR) system at Columbia University Irving Medical Center (CUIMC), the demands of the novel coronavirus disease 2019 (COVID-19) pandemic forced an abrupt reallocation of resources away from EHR adoption. To assist staff in focusing on techniques for improving EHR utilization, an optimization methodology was designed referencing the Consolidated Framework for Implementation Research (CFIR) approach.

Methods The study was performed using a methodology that comprised of two primary components as follows: (1) analysis of qualitative and quantitative data and (2) participation of frontline staff in project work groups. Working groups mapped out the current state of the identified workflows, designed and implemented interventions, monitored the effectiveness of each intervention, and scaled the proposed changes. Results As a result of the optimization methodology, clinical and operational workflows improved in the pilot department. Operationally, the pilot department increased enrollment of patients in the virtual patient portal by $20 \%$, increased schedule utilization by $25 \%$, and reduced average check-in time by $19 \%$. Clinically, the pilot department had a statistically significant increase in dictation and NoteWriter tool note composition from their baseline month to their observed month. Compared with the control department, the pilot department had a statistically significant increase in SmartTool and dictation note composition. The control department showed smaller increases, and in some cases a decline in performance, in these areas of operational and clinical workflows.

Conclusion The CFIR framework helped design an optimization methodology by applying a set of constructs to support effective organizational optimization, accounting for inner and outer settings. Through this methodology, the inner setting was received

March 24, 2021

accepted after revision

November 3, 2021
DOI https://doi.org/

$10.1055 / \mathrm{s}-0041-1741479$

ISSN 1869-0327. (c) 2022. The Author(s).

This is an open access article published by Thieme under the terms of the Creative Commons Attribution-NonDerivative-NonCommercial-License, permitting copying and reproduction so long as the original work is given appropriate credit. Contents may not be used for commercial purposes, or adapted, remixed, transformed or built upon. (https://creativecommons.org/ licenses/by-nc-nd/4.0/)

Georg Thieme Verlag KG, Rüdigerstraße 14, 70469 Stuttgart, Germany 
supported in leading the identification and execution of interventions targeted to impact the outer setting. The phase-1 data at CUIMC suggest this strategy is effective in identifying opportunities, implementing interventions and creating a scalable process for continued organizational optimization.

\section{Background and Significance}

There has been an increase of adoptions of new electronic health record (her) systems by health care institutions over the years with a goal of standardizing and improving the quality of care that they can provide to their patients. ${ }^{1}$ Throughout the process of EHR implementation, challenges may arise and ways to improve the use and efficiency of the EHR may also be recognized. Previous studies have shown one reason that separates "good" versus "great" EHR implementations in ambulatory settings is the additional focus on improvement over time and standardization through optimization. ${ }^{1}$ In fact, Moon et al stressed how "such optimization following the go-live is critical to successful implementation in ambulatory settings." 2 Ultimately, finding ways to optimize EHR usage after it has undergone implementation "is a critical step toward achieving the EHR's potential as a tool for facilitating high quality and efficient care." 3

The focus and approach that organizations take when optimizing an EHR may differ based on each organization's goals and priorities. While some organizations may focus optimization efforts on patient outcomes (such as reducing blood clots and catheter-associate urinary tract infections by putting alerts in their EHR during their optimization phase), others may focus on optimizing the core clinical workflow at the enterprise level. ${ }^{4}$ After having gone through a large structural change with implementation of a new EHR system, in February 2020 and in the midst of the novel coronavirus, the novel coronavirus disease 2019 (COVID-19) global pandemic, $^{5}$ Columbia University Irving Medical Center (CUIMC) had an immediate need to create and adopt an optimization methodology of clinical and operational best practices to effectively deliver the new model of patient care. The COVID-19 pandemic forced providers and staff in CUIMC to quickly adapt and learn the new EHR system, given that the pandemic hit only 1 month after the EHR go-live date. Given other priorities, including ways to keep all employees safe, one can say that the implementation was an expedited process and not a primary focus. As a result, not all stakeholders learned to utilize the new EHR system effectively. There was great focus at CUIMC on one optimization process identified by Moon et al which was increasing EHR efficiency by optimizing practice/process workflows. ${ }^{2}$ The design and delivery of the optimization methodology at CUIMC was studied through the use of the Consolidated Framework for Implementation Research (CFIR) model to ensure the maximum adoption of these best practices in the study's pilot department. The pilot and the control groups were similar subspecialties in size, volume of patients, types of visits, and user level of proficiency in the EHR. The pilot department was chosen because its users are early adopters and are led by engaged and supportive leadership.

\section{Overview of the Consolidated Framework for Implementation Research Model}

The multilayered approach of the CFIR ${ }^{6}$ provides grounds for understanding how evidence-based practices are best integrated and adopted among multiple external and internal variables. Building on Harrison's ${ }^{7}$ open systems model, the CFIR model enforces evaluation of the climate, typically defined by individuals of multiple levels of an organization, their respective interactions, and the cumulative impact across the following five domains of the model: intervention, outer setting, inner setting, individual characteristics, and process, as depicted in - Fig. 1.

The outer setting can be understood as the governing policies and procedures of an organization, as well as the patients and their respective needs and resources. The inner setting represents an organization's structural characteristics, the culture and implementation climate, resources available to local teams and the ability of engaged leadership to provide clear goals and feedback. The success of adaptability of a given best practice across the course of any given process is determined by the interaction between members of the outer setting and those of the inner setting. The CFIR model proposes creating an environment of psychological safety, providing protected time and venues to enable creative thinking and evaluation, and showcasing the importance of collaboration and partnership, as the most critical competencies required of the outer setting. ${ }^{8}$

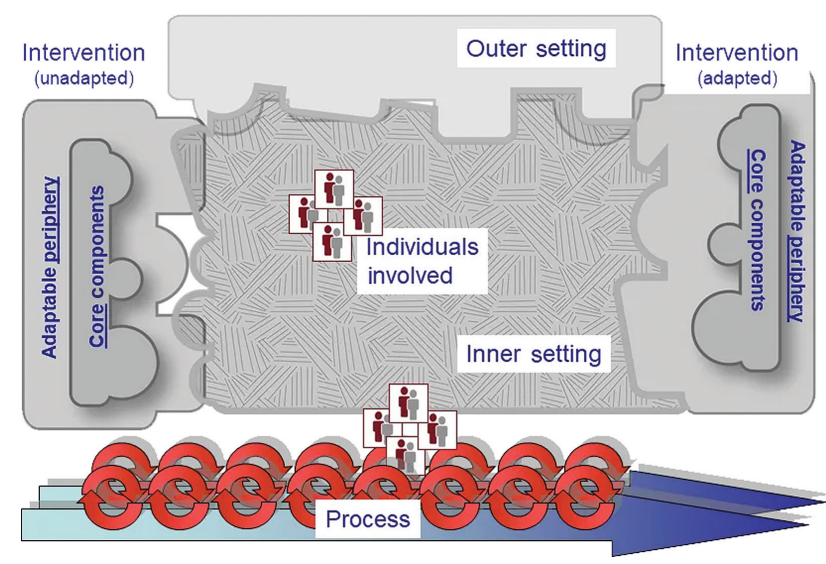

Fig. 1 The five domains of the CFIR model visualizing the inner and outer settings and the movement from unadapted to adapted of an intervention in any given process. CFIR, Consolidated Framework for Implementation Research. 
The CFIR model also provides guidance around assessing certain intervention characteristics such as adaptability, trial ability, relative advantage, and complexity. These factors are critical to evaluate when introducing best practices to the inner setting members and appropriate support structures need to be in place within the environment to enable successful adoption.

With respect to the CFIR model and this study, the pilot department is the system of focus. Therefore, the individuals involved are to be considered the inner setting. Everything external to that is considered the outer setting, inclusive of the organizational governing policies and resources, the leadership, and COVID-19.

The questions of interest discussed in this paper are mentioned below:

- Is the proposed framework, utilizing the CFIR model effective in guiding inner settings to identify and execute optimization opportunities?

- As a result of the optimization efforts of the inner setting, can the pilot ambulatory clinical department improve key performance metrics when compared with a control group?

\section{Methods}

\section{Study Design}

CUIMC has an established Organization Effectiveness and Optimization (OEO) team whose primary objective was to enable the organization to proactively meet strategic goals by designing targeted, data-driven, and cost-effective interventions at the people, process, and technology levels. As the internal Organization Development practitioners, this group designed the optimization methodology with two primary objectives: (1) utilize data to assess and monitor optimization progress, and (2) engage frontline staff to create accountability for results in the change process. Facilitators of the EHR optimization process included a clear vision, committed leaders, dedicated resources, stakeholder engagement, and workflow analysis. ${ }^{9}$ Within the context of the CFIR model, the organization development team was part of the outer setting and supported the knowledge transfer and provision of tools and resources during the optimization methodology implementation. The inner setting, comprised of the clinical pilot department, was accountable for the execution and success of the intervention. Understanding these two competencies, the methodology was structured into two layers: the first layer was at the ambulatory department level where workflows were divided into operational and clinical groups. The second layer was at the organization level which was designed to support all ambulatory departments through the implantation of learning models and cross-specialty collaborations (-Fig. 2).

\section{Operational and Clinical Workgroups}

The department level operational and clinical work streams were supported by workgroups. The operational workgroup consisted of members of the frontline staff representing each of the staff roles of that practice. Frontline stakeholders

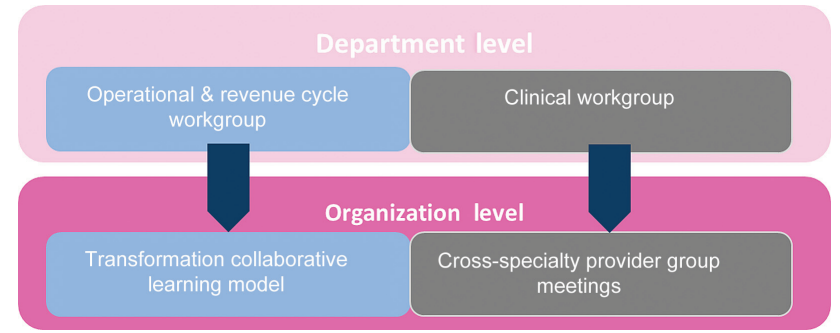

Fig. 2 The meeting structures at the department and organization level visualizing the cascading nature of the local workgroups to the larger organization model.

included medical receptionists, practice assistants, medical assistants, and the Director of Operations. The medical receptionists were tasked with administrative duties such as scheduling, greeting patients, responding to messages on EHR, and checking patients in and out. The practice assistants were responsible for surgical scheduling, referral authorizations, work queues, and responding to messages on EHR. The medical assistants managed patient flow through the practice and supported physicians during inperson visits by taking patient vitals and assisting with procedures. Lastly, the Director of Operations was responsible for operational support and clinical oversight of different practice locations. The clinical workgroup consisted of the department's clinical lead physician and additional EHR personalization leads who were tasked with personalizing available tools in EHR to enable efficiencies of clinical workflows.

Members of both these workgroups served as the opinion leaders and were responsible for executing and evaluating the optimization efforts, as it related to the CFIR model. Both workgroups utilized an agenda and minutes for each weekly meeting for the duration of the study. The expectations of the department leadership were to provide protected time to the workgroups to implement and monitor changes, as well as to provide communication channels for messaging and soliciting feedback from the rest of the department.

One of the primary goals of the workgroups was to create an environment to support constructive feedback and to allow for full transparency of successes and lessons learned. Additionally, both workgroups needed to maintain cross-group communication to ensure alignment on workflows and to understand the impact of their respective interventions.

The organization layer was designed to bring together the individual department level workgroups to enable best practice sharing and group learning among the organization. For the operational work stream, these events were the Transformation Collaborative Meetings and for the clinical work stream, these events were the Cross-Specialty Provider Group Meetings.

\section{Optimization Methodology Phases}

The process or implementation was further divided into three distinct phases as described hereinafter.

\section{Phase 1}

The first phase was to complete a current state assessment of the prioritized workflows. The current state assessment was 
performed by the OEO team and the operational workgroup. This was done through conducting observational studies within the practice setting, observing high performing clinicians to identify best practices, and reviewing baseline metrics/key performance indicators (KPIs). The operational and clinical metrics, which were reviewed, were retrieved from EHR data extracts.

The high performing clinicians were identified with the guidance from the clinical lead reviewing the previously mentioned metrics. The sessions were conducted by the OEO team both in person and via video calls depending on the availability of the providers. The OEO team met with each provider once for the duration of an hour. This process helped in understanding the evidence strength and quality of the given workflows. The current state process maps were reviewed and validated during the weekly workgroup meetings. During this phase, a preproject staff survey was administered to the department staff to identify additional opportunities for optimization and learning gaps. This survey was designed by OEO team and was administered electronically to the department staff.

\section{Phase 2}

The second phase was designing interventions that included the needed core components and accounted for the adaptable periphery to ensure maximum adaptability and trial ability. The core components included the respective clinical and operational KPIs, and feedback from frontline staff. The adaptable periphery was defined by level of engagement outside of the workgroup to adopt the interventions. Once created, the intervention was piloted at a single clinical practice location (pilot department) to optimize target workflows which were set by organizational leadership, and to bring them closer to the desired future state. Weekly data were reviewed to monitor this implementation and feedback was continuously solicited by the workgroup members of their peers to understand the impact of the interventions.

\section{Phase 3}

The third phase was scaling up the adoption of the successful intervention by other clinical practice locations with continuous data evaluation. The clinical workflows were optimized through the Provider Group Meeting (PGM) structure: monthly sessions designed to bring together representative providers from their respective departments to learn best practices from each other and to communicate new system changes. Due to the limitations brought about with the pandemic, the PGMs were conducted virtually. In addition to the PGMs, the organization development team conducted personalization sessions for providers when data and observations indicated opportunities for gained efficiencies. Pre- and postproject clinical staff surveys were administered electronically among the clinical department staff to identify additional learning gaps and opportunities for improvement.

These surveys were entirely opinion-based and were not intended to validate the proposed methodology. This methodology is summarized in - Fig. 3 .

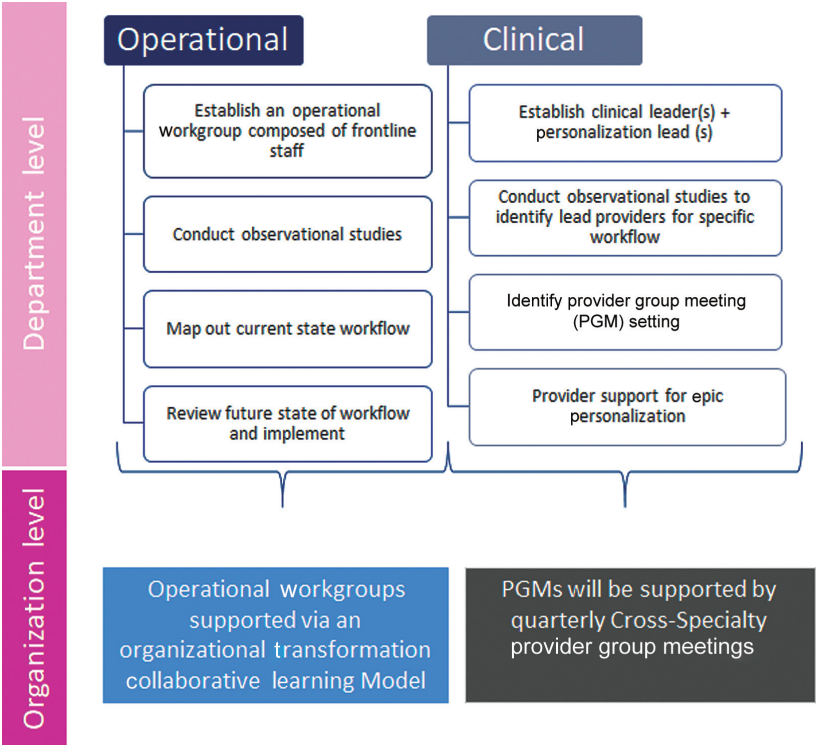

Fig. 3 Visual representation of the optimization methodology highlighting the specific details of the different phases of the at the department level and the cascading of those cumulative steps to the organization level.

\section{Implementation of the Optimization Methodology in Pilot Department}

The optimization methodology was first implemented within the selected pilot department to improve a selected set of their operational and clinical workflows.

\section{Operational Workgroup Workflows}

Within this context, the outcomes were the identified workflows measured by the metrics identified on EHR, and the goal was achieving the established targets for each respective workflow. The operational workgroup, outlined in -Table 1, identified the following workflows as targets for optimization:

- MyChart activation and usage (patient facing application).

- eCheck-in (via the MyChart patient facing application).

- Average registration time.

- Provider schedule utilization (the ratio of time slots available to time slots used to see patients).

Different interventions were developed to help improve the different operational workflows. The interventions designed to increase MyChart enrollment included the utilization of standardized scripts during previsit phone calls to patients, decreasing the overall number of phone calls made to patients by eliminating that task from other workflows where it was found to be duplicative, and provision of support materials that was shared and reviewed with the staff to ensure that they were all using the most current resources and were familiar with the contents. The interventions used to increase the use of the electronic check-in (eCheck-in) process through the MyChart portal and application included utilization of scripts to actively encourage patient use of the feature, automated appointment reminder messages across the organization that had already been updated to encourage e-check in reminders and integration 
Table 1 Overview of evaluated operational metrics

\begin{tabular}{|l|l|}
\hline $\begin{array}{l}\text { Operational } \\
\text { metrics }\end{array}$ & Definition \\
\hline $\begin{array}{l}\text { MyChart } \\
\text { activation }\end{array}$ & $\begin{array}{l}\text { Percent of patients seen in a department } \\
\text { with an active MyChart account }\end{array}$ \\
\hline eCheck-In & $\begin{array}{l}\text { The percentage of arrived appointments } \\
\text { where eCheck-in is completed. Walk-in } \\
\text { appointments are excluded }\end{array}$ \\
\hline $\begin{array}{l}\text { Schedule } \\
\text { utilization }\end{array}$ & $\begin{array}{l}\text { Displays the schedule utilization of a } \\
\text { provider. This is calculated as all booked } \\
\text { time, plus late cancel time, divided by the } \\
\text { providers' templated regular time }\end{array}$ \\
\hline $\begin{array}{l}\text { Average } \\
\text { regular time }\end{array}$ & $\begin{array}{l}\text { This metric indicates how much time per } \\
\text { patient is spent updating registration } \\
\text { information }\end{array}$ \\
\hline
\end{tabular}

Abbreviation: HER, electronic health record.

Source: EHR dashboard reports.

of mobile kiosk stations, and a patient greeter to try and facilitate the adoption of low-touch methods of patient eCheck-in. The interventions utilized to reduce the average time to complete the registration process included participation in a curated workflow review session conducted by the enterprise training team by all department staff responsible for registration-related functions.

The project timeframe coincided with an organizational wide initiative to optimize provider schedule templates, to improve schedule utilization rates, and to support an increase in postpandemic in-person visit volume.

\section{Clinical Workgroup Workflows}

The clinical workgroup, outlined in - Table 2, prioritized the following two clinical workflows:

1. Clinical patient note composition.

2. Turnaround time on a select set of patient messages: results, medical advice requests, patient calls, and prescription refill authorizations.

Personalization sessions and a PGM were scheduled to target improvements in these two workflows. The personalization lead and organization development team facilitator conducted sessions with 10 out of the 13 attending physicians in the pilot department.

The interventions focused on decreasing manual note composition through the development of additional note templates and education on EHR functionalities to ease documentation burden. During the PGM, content was designed to assist clinical staff adopt additional functionalities within EHR InBasket (messaging feature), as well as develop training content on how to use the InBasket more efficiently to improve turnaround time.

The control department, a matched surgical subspecialty department, did not have any established workgroups conducting targeted interventions on clinical and operational workflows utilizing the developed optimization methodology during this project period.
Table 2 Overview of evaluated clinical metrics

\begin{tabular}{|l|l|}
\hline Clinical metrics & Definition \\
\hline $\begin{array}{l}\text { Turnaround time- } \\
\text { results }\end{array}$ & $\begin{array}{l}\text { Average number of days a provider } \\
\text { took to mark a results message as } \\
\text { done }\end{array}$ \\
\hline $\begin{array}{l}\text { Turnaround time- } \\
\text { medical advice } \\
\text { request }\end{array}$ & $\begin{array}{l}\text { Average number of days a provider } \\
\text { took to mark a medical advice } \\
\text { request as done }\end{array}$ \\
\hline $\begin{array}{l}\text { Manual note } \\
\text { composition }\end{array}$ & $\begin{array}{l}\text { Percentage of note content } \\
\text { generated by the provider using } \\
\text { manual methods }\end{array}$ \\
\hline $\begin{array}{l}\text { NoteWriter note } \\
\text { composition }\end{array}$ & $\begin{array}{l}\text { Percentage of note content } \\
\text { generated by the provider using } \\
\text { SmartBlocks, Macros or voice } \\
\text { recognition in a SmartBlock }\end{array}$ \\
\hline $\begin{array}{l}\text { SmartTools note } \\
\text { composition }\end{array}$ & $\begin{array}{l}\text { Percentage of note content } \\
\text { generated by the provider using } \\
\text { SmartLinks, SmartTexts, } \\
\text { SmartPhrase, or SmartLists }\end{array}$ \\
\hline $\begin{array}{l}\text { Dictation note } \\
\text { composition }\end{array}$ & $\begin{array}{l}\text { Percentage of note content } \\
\text { generated by the provider using } \\
\text { voice recognition (e.g., M*Modal } \\
\text { fluency direct) }\end{array}$ \\
\hline composition & $\begin{array}{l}\text { Percentage of note content } \\
\text { generated by the provider using } \\
\text { copied, pasteboard, copy } \\
\text { previous/forward }\end{array}$ \\
\hline
\end{tabular}

Abbreviation: HER, electronic health record.

Source: Provider efficiency profile via EHR data.

\section{Results}

To evaluate whether the optimization methodology was effective in improving the operation and clinical workflows, baseline operational and clinical data were collected in May 2020, and the poststudy data were collected in August 2020. Metric data were collected from the pilot department, and control data were captured from a comparable surgical subspecialty department with similar volumes and clinical services.

\section{Clinical Results}

Optimization efforts were completed in August 2020, whereupon usage pattern data were compared with preintervention (SP) time point in May 2020. An increase in SmartTool usage was noted by $5.7 \%$ and a decrease in manual note composition was observed by $6.09 \%$. Comparing the baseline data to the August data for the InBasket turnaround time on patient related messages, a decrease in all message types except for medication advice was noted. It is worth noting that the August data met and exceeded the EHR community benchmark for turnaround time. CUIMC had set a unique target for 1-day turnaround on all patient related messaging. All metrics, EHR community benchmarks, and CUIMC targets can be referenced in -Table 3 .

Compared with the control department, the pilot department met targets for InBasket turnaround time, time in notes, and dictation note composition. Although metrics 
Table 3 Clinical metrics data for pilot and control departments

\begin{tabular}{|l|l|l|l|l|l|l|l|l|}
\hline & \multicolumn{2}{|l|}{ Pilot department } & \multicolumn{2}{l|}{ Control department } \\
\cline { 2 - 8 } & Baseline & Comparison & $\begin{array}{l}\text { Variance from } \\
\text { baseline }\end{array}$ & $\begin{array}{l}\text { Variance from } \\
\text { target }\end{array}$ & Baseline & Comparison & $\begin{array}{l}\text { Variance } \\
\text { from } \\
\text { baseline }\end{array}$ & $\begin{array}{l}\text { Variance } \\
\text { from } \\
\text { target }\end{array}$ \\
\hline $\begin{array}{l}\text { Turnaround time, results (d) } \\
\text { target 7.1 }\end{array}$ & 5.63 & 3.21 & $-43.00 \%$ & Target met & 5.22 & 2.69 & $-48.47 \%$ & Target met \\
\hline $\begin{array}{l}\text { Turnaround time, medical } \\
\text { advice request (d) target } \\
2.8\end{array}$ & 0.94 & 0.48 & $-48.70 \%$ & Target met & 1.38 & 3.23 & $134.06 \%$ & $-13 \%$ \\
\hline $\begin{array}{l}\text { Manual note composition } \\
\text { target 8.5\% }\end{array}$ & $17 \%$ & $11.50 \%$ & $-34.08 \%$ & $-26 \%$ & $16.26 \%$ & $14.75 \%$ & $-9.29 \%$ & $-42 \%$ \\
\hline $\begin{array}{l}\text { Note writer note } \\
\text { composition target 8.8\% }\end{array}$ & $0 \%$ & $0.48 \%$ & $13.43 \%$ & $1741 \%$ & $4.37 \%$ & $6.44 \%$ & $47.37 \%$ & $37 \%$ \\
\hline $\begin{array}{l}\text { Smart tools note } \\
\text { composition target 59\% }\end{array}$ & $52 \%$ & $55 \%$ & $5.19 \%$ & $7 \%$ & $47.75 \%$ & $52 \%$ & $8.90 \%$ & $13 \%$ \\
\hline $\begin{array}{l}\text { Dictation note composition } \\
\text { target 6.6\% }\end{array}$ & $5 \%$ & $6.40 \%$ & $39.19 \%$ & Target met & $0.00 \%$ & $0.00 \%$ & $0.00 \%$ & $-100 \%$ \\
\hline $\begin{array}{l}\text { Copy/paste note } \\
\text { composition target 16\% }\end{array}$ & $25 \%$ & $27 \%$ & $6.43 \%$ & $-40 \%$ & $30.27 \%$ & $26 \%$ & $-14.11 \%$ & $-38 \%$ \\
\hline
\end{tabular}

Table 4 Nonparametric hypothesis test-control versus pilot department

\begin{tabular}{|l|l|l|l|}
\hline Ho & \multicolumn{2}{|l|}{ There is no difference in the distribution of the two populations } \\
\hline Ha & \multicolumn{2}{|l|}{ There is a difference in the distribution of the two populations } \\
\hline Metric & Z observed & Z critical & Conclusion \\
\hline Copy paste composition & 0.5045 & 1.96 & Fail to reject Ho \\
\hline Manual composition & 1.4775 & 1.96 & Fail to reject Ho \\
\hline NoteWriter composition & -0.5225 & 1.96 & Fail to reject Ho \\
\hline SmartTool composition & -1.9821 & 1.96 & Reject Ho \\
\hline Dictation composition & -8.9013 & 1.96 & Reject Ho \\
\hline $\begin{array}{l}\text { Turnaround time for patient } \\
\text { medical advice requests }\end{array}$ & 0.7800 & 1.96 & Fail to reject Ho \\
\hline Turnaround time for patient results & -0.2523 & 1.96 & Fail to reject Ho \\
\hline
\end{tabular}

for manual note composition and SmartTool note composition did not meet desired targets, the metrics were trending positively throughout the pilot department optimization study. The control group met one metric, turnaround time for results messages which was met in the baseline and subsequent data periods.

Clinical data were analyzed using a nonparametric hypothesis test to determine the statistical significance of the results. The nonparametric hypothesis test was utilized due to the relatively small sample size, continuous data, and the inability to assume normal data distribution. Overall, the pilot department had a statistically significant increase in dictation ( $Z$ observed of -3.2909 with a $Z$ critical of 1.96 ) and NoteWriter tool ( $Z$ observed of -3.1754 with a $Z$ critical of 1.96) note composition from their baseline month to their observed month. Compared with the control department, the pilot department had a statistically significant increase in SmartTool ( $Z$ observed of -1.9821 with a $Z$ critical of 1.96 ), and dictation ( $Z$ observed of -8.9013 with a $Z$ critical of 1.96 ) note composition. We claim this with 95\% certainty. See -Tables 4 and 5 for statistical analysis. Quantitative data from EHR cannot fully reflect the proficiency levels across the pilot specialty. The clinical survey conducted before and after implementation provided qualitative insights into how clinical staff perceived EHR proficiency. The survey results were used to identify trends for optimization opportunities across the specialty. Based on the trends, content was designed to be presented at the PGMs. Content was presented from the Personalization Leads or Subject Matter Experts (SME). The SMEs were identified via review of the EHR export data incorporating subjective feedback from the Clinical Leads in the department. Observations were conducted on the SMEs to verify workflow efficiency. The key finding from the survey responses was an $80 \%$ perceived efficiency loss with InBasket management. This fortified prioritization of the InBasket Management as 
Table 5 Nonparametric hypothesis test-pilot department baseline month verses observed month

\begin{tabular}{|l|l|l|l|}
\hline Ho & \multicolumn{2}{|l|}{ There is no difference in the distribution of the two populations } \\
\hline $\mathrm{Ha}$ & \multicolumn{2}{|l|}{ There is a difference in the distribution of the two populations } \\
\hline Metric & $Z$ observed & Z critical & Conclusion \\
\hline Copy paste composition & -0.2887 & 1.96 & Fail to reject Ho \\
\hline Manual composition & 1.5011 & 1.96 & Fail to reject Ho \\
\hline NoteWriter composition & -3.1754 & 1.96 & Reject Ho \\
\hline SmartTool composition & -0.9238 & 1.96 & Fail to reject Ho \\
\hline Dictation composition & -3.2909 & 1.96 & Reject Ho \\
\hline $\begin{array}{l}\text { Turnaround time for patient } \\
\text { medical advice requests }\end{array}$ & 0.1952 & 1.96 & Fail to reject Ho \\
\hline Turnaround time for patient results & & 1.96 & Fail to reject Ho \\
\hline
\end{tabular}

a secondary optimization focus to note writing. In addition to note writing and InBasket management, PGM content included reporting and billing workflows in EHR. The PGM platform was also used to discuss recent changes and issues from EHR upgrades. Provider optimization benefits were realized via a cyclical model of personalization sessions, PGMs, and data monitoring.

\section{Operational Results}

-Table 6 depicts the results achieved from the operational metric workflow evaluation of both the pilot and control departments. At the start of the project period, the pilot department had a baseline MyChart activation rate of 39\% and at the end of the period the activation rate had increased to $49 \%$. When comparing the project department's variance in MyChart activation rates to the control department, it was noted that there was a greater increase in the pilot department's activation rates. The utilization of eCheck-in through the MyChart application was also identified as a key area for improvement; however, the use of eCheck-in saw a decrease over the project period (25-19\% of all visits). This change coincided with the sharp increase in the department's inperson patient visit volume (total number of video visits was relatively constant with 265 visits in May and 223 visits in July). The control department saw a slightly larger decrease in eCheck-in percentages (the pilot department saw a variance of $-6 \%$ compared with $-11.5 \%$ in the control department).

Average registration times at the start of the project period were already below the CUIMC target of 5 minutes per patient. Overall, there was a decrease in registration times over the course of the project period from 4 minutes and 33 seconds to 3 minutes and 51 seconds representing a savings of 42 seconds per patient registration. This decrease in registration time over this period also occurred at a time when patient visit volume had increased from 1,264 visits in May to 3,721 visits in July (a 194.4\% increase over their baseline). The control department also saw an increase in visit volume over the same period (from 2,226 visits in May to 3,980 visits in July or an increase of $78.8 \%$ ) but saw registration time per patient increase from 3 minutes 14 seconds to 3 minutes 53 seconds (an average increase of 39 seconds per patient registration).

Schedule utilization percentage increased from 58 to $72 \%$ but it was unclear how much of this was due to pent-up demand for in-person visits compared with optimization of schedule templates for providers (overall visit volume

Table 6 Operational metrics data for pilot and control departments

\begin{tabular}{|l|l|l|l|l|l|l|l|l|}
\hline & \multicolumn{2}{|l|}{ Pilot department } & \multicolumn{2}{l|}{ Control department } \\
\cline { 2 - 9 } & Baseline & Comparison & $\begin{array}{l}\text { Variance } \\
\text { from } \\
\text { baseline }\end{array}$ & $\begin{array}{l}\text { Variance } \\
\text { from target }\end{array}$ & Baseline & Comparison & $\begin{array}{l}\text { Variance } \\
\text { from } \\
\text { baseline }\end{array}$ & $\begin{array}{l}\text { Variance } \\
\text { from } \\
\text { target }\end{array}$ \\
\hline $\begin{array}{l}\text { MyChart activation } \\
\text { target 75\% }\end{array}$ & $38.80 \%$ & $46.60 \%$ & $20 \%$ & $61 \%$ & $57.14 \%$ & $63.14 \%$ & $11 \%$ & $19 \%$ \\
\hline eCheck in target 60\% & $24.78 \%$ & $19.12 \%$ & $-23 \%$ & $68 \%$ & $50.47 \%$ & $38.64 \%$ & $-23 \%$ & $55 \%$ \\
\hline $\begin{array}{l}\text { Telehealth \% target 30- } \\
60 \%\end{array}$ & $21.47 \%$ & $6.08 \%$ & $-72 \%$ & & $64.90 \%$ & $30.01 \%$ & $-54 \%$ & Target met \\
\hline $\begin{array}{l}\text { Schedule utilization } \\
\text { target 85\% }\end{array}$ & $57.94 \%$ & $71.56 \%$ & $24 \%$ & $19 \%$ & $50.30 \%$ & $30.01 \%$ & $85 \%$ & $183 \%$ \\
\hline $\begin{array}{l}\text { Average regular time } \\
\text { target <5 minutes }\end{array}$ & $4: 44$ & $3: 51$ & $-19 \%$ & Target met & $3: 14$ & $3: 53$ & $20 \%$ & Target met \\
\hline
\end{tabular}


increased by $194.4 \%$ for the pilot department during this time). By comparison, the control department saw a decrease in schedule utilization from $50 \%$ in May to $30 \%$ in July. It was not immediately apparent why there was a decrease in schedule utilization in the control department at a time when visit volume had increased for the control group by $79 \%$ over the project period. Monitoring of the effectiveness of schedule optimization was ongoing and needed further evaluation as in-person visit volumes approached prepandemic levels across the institution.

\section{Discussion}

Using the CFIR construct to evaluate implementation of optimization methodology demonstrated an increased likelihood of attaining optimization targets for clinical and operational workflows when an organization creates structures to support and facilitate engaged members of an inner setting to create workgroups that utilize essential core components and relevant adaptable variables to design an intervention. There are numerous other variables that contribute to these outcomes and the optimization methodology demonstrates its utility in contributing to this mix.

Through the course of the workgroup meetings, there were several barriers identified including time limitations and resource needs that occasionally inhibited members from attending the weekly workgroup meetings or engaging in protected time to conduct observations on intervention adoption. Almost all workgroup meetings were conducted virtually which in some cases impacted the level of engagement from all users. In addition, the rate of scaling up an intervention was sometimes impeded by competing priorities of the department and challenges aligning priorities shared by the operational and clinical leads. The project could have benefited from a cross-over between the clinical and operational workgroups to ensure that department operational and clinical leads were aligned on optimization goals. This change would enable the most efficient use of time during workgroup meetings.

The success of interventions related to enrollment in the patient portal was determined by technological, social, and language barriers intrinsic to the patient population of the pilot department. Specifically, patients often required interpreter services during outreach calls or enrollment materials and resources in their native language. This had direct impact on the eCheck-in rate which was a metric the pilot department continues to monitor post the project period.

The personalization sessions supported improved provider efficiency when delivered with a targeted approach but also with on-going monitoring and touch points. The limited amount of time the organization development team could support the project was a barrier to longitudinal monitoring. Additionally, the department personalization leads lacked the bandwidth for extended optimization efforts due to clinical practice demands.

Overall, the methodology, framework, and strategy utilized to implement the initial phase of optimization efforts appear to provide an effective structure that can be replicat- ed and scaled in a manner that would provide the organization with a significant return of investment. Additional investment in personnel and resources may provide a durable support structure to facilitate longitudinal optimization efforts and sustainability across a larger number of clinical departments. Moreover, since multiple organizations across the country are on EHR, using the CFIR model is translated to others who are using interoperable EHRs.

\section{Limitations}

The OEO team implemented the optimization methodology with the pilot department simultaneously with other organizational initiatives during the middle of a pandemic, thus limiting full allocation of resources to the effort. All Provider Group Meetings were held virtually due to the pandemic which could have impacted engagement. Ideally, these collaborative sessions would be held in person and depending on the specific content, as working sessions. Additionally, clinical staff familiarity with how to navigate within the EHR environment was increasing contemporaneously with the optimization effort, and thus some gains in efficiency would be expected from this inherent familiarity. Analysis of data from the control department suggests that additional gains were due to the optimization effort. Due to data limitations, direct and exact correlation between this initiative and the improvement in the targeted clinical and operational workflows for the pilot department cannot be determined. The assumption was that this methodology provided a framework to the pilot department which was useful in the improvements noted. However, this was only shown for one ambulatory department and the methodology will need to be studied through multiple phases with additional ambulatory departments. Additionally, the lack of longer term longitudinal assessments was a limitation to this study.

The pilot and control department, while representing two different clinical specialties, were selected due to comparable patient panel size, staffing ratios, and new patient visit and follow-up visit volumes. However, by virtue of being different clinical specialties, there are intrinsic differences, that is, a limitation of the study.

Competing priorities, even in the setting of a tuned process, sets participants' time commitment as a limiting factor. Further evaluation should determine if this pilot supplanted less effective optimization work with more effective optimization efforts to assess idealized optimization protocols. Additionally, without a professional statistician on the team, statistical analysis is limited.

\section{Conclusion}

Following the implementation of a new her, while reacting to a global pandemic, CUIMC recognized the need to assist clinical staff in optimizing their use of EHR to adapt to the increasing demands of a rapidly changing environment. Designing the optimization methodology using the CFIR model ensured appropriate accounting of multiple external and internal variables. This optimization methodology 
enabled staff to utilize the knowledge and resources available to enhance their delivery of patient care. Engaging multiple levels of an organization in a protected workspace encouraged collaboration and partnership to develop original solutions to critical efficiency issues. Dedicating a team to guiding the organization through the implementation of this methodology allowed the end users to maximize their time in the engagement, focusing on creativity, execution, and adoption. The interventions identified were clearly initiated and executed by the inner setting but designed for the outer setting. These interventions were successful because they accounted for the individual characteristics and tailored processes that were effective for specific use cases. The pilot data at CUIMC has demonstrated that utilizing the CFIR framework can be effective for guiding an organization through identifying optimization opportunities including enhancing clinical and operational workflows and collaborating in the implementation of interventions.

\section{Clinical Relevance Statement}

The information provided through this manuscript can provide a reference framework for ambulatory practices to design an optimization methodology to apply to both operational and clinical workflows. It also provides a reference on what specific key performance indicators can be reviewed when conducting an optimization project.

\section{Multiple Choice Questions}

1. What was a key inner setting component identified in the optimization methodology?
a. Data
b. Workgroups
c. Technology
d. Policies and procedures

Correct Answer: The correct answer is option b. Workgroups, operational and clinical workgroups comprised of departmental frontline staff, are a key component to the first stage of the optimization methodology.

2. Through what format was the clinical workflow optimization designed?
a. Personalization sessions
b. Workgroup meetings
c. Provider group meetings
d. Quarterly group meetings

Correct Answer: The correct answer is option c. Provider group meetings, these were the monthly sessions where all providers of a department come together for best practice sharing and peer learning.

\section{Protection of Human and Animal Subjects}

No human subjects were involved throughout the course of this study.

Conflict of Interest

None declared.

\section{References}

1 McAlearney AS, Song PH, Robbins J, et al. Moving from good to great in ambulatory electronic health record implementation. J Healthc Qual 2010;32(05):41-50

2 Moon MC, Hills R, Demiris G. Understanding optimization processes of electronic health records (EHR) in select leading hospitals: a qualitative study. J Innov Health Inform 2018;25(02): 109-125

3 Pandhi N, Yang W-L, Karp Z, et al. Approaches and challenges to optimising primary care teams' electronic health record usage. Inform Prim Care 2014;21(03):142-151

4 Leventha R. Post-implementation advancements: Leaders from various healthcare organizations explain how they have been moving forward with their EHRs following implementation. Accessed December 10, 2021 at: https://link.gale.com/apps/doc/A366347006/ HRCA?u=columbiau\&sid=summon\&xid=72579fcc

5 World Health Organization. Responding to community spread of COVID-19: interim guidance. Accessed December 10, 2021 at: https://www.who.int/publications/i/item/responding-to-communityspread-of-covid-19

6 The Consolidated Framework for Implementation Research. Accessed December 10, 2021 at: https://cfirguide.org/

7 Harrison MI. Diagnosing Organizations: Methods, Models, and Processes. Thousand Oaks, CA: Sage Publications Inc.; 2005

8 Harrison MI, Shortell M. Multi-level analysis of the learning health system: Integrating contributions from research on organizations and implementation. Learning Health Systems 2020;5 (02). Doi: 10.1176/appi.ps.202000257

9 Sieja A, Kim E, Holmstrom H, et al. Multidisciplinary sprint program achieved specialty-specific EHR optimization in 20 clinics. Appl Clin Inform 2021;12(02):329-339 